Ларченко Ю. Г., Бирюков Е. С.

ИНСТРУМЕНТЫ ПРИВЛЕЧЕНИЯ И УДЕРЖАНИЯ КЛИЕНТОВ В СЕТИ ИНТЕРНЕТ

Ларченко Ю. Г., Бирюков Е. С.

Yu. G. Larchenko, E. S. Biryukov

ИНСТРУМЕНТЫ ПРИВЛЕЧЕНИЯ И УДЕРЖАНИЯ КЛИЕНТОВ В СЕТИ ИНТЕРНЕТ

\title{
TOOLS TO ATTRACT AND RETAIN CUSTOMERS IN THE INTERNET NETWORK
}

Ларченко Юлия Геннадьевна - кандидат экономических наук, доцент кафедры сервиса и торгового дела Комсомольского-на-Амуре государственного университета (Россия, Комсомольск-на-Амуре). Е-таil: 1_uliya g@mail.ru.

Ms. Yulia G. Larchenko - PhD in Economics, Associate Professor, Department of Service and Trade, Komsomolsk-on-Amur State University (Russia, Komsomolsk-on-Amur). E-mail: 1_uliya_g@mail.ru.

Бирюков Евгений Сергеевич - магистр направления «Торговое дело» Комсомольского-на-Амуре государственного университета (Россия, Комсомольск-на-Амуре). E-mail: Freakmass@yandex.ru.

Mr. Evgeny S. Biryukov - Master of Business Administration, Komsomolsk-on-Amur State University (Russia, Komsomolsk-on-Amur). E-mail: Freakmass@yandex.ru.

Аннотация. В статье рассматривается понятие электронной коммерции, основные инструменты по привлечению и удержанию целевых клиентов с учётом их характеристик и особенностей.

Summary. The article discusses the concept of e-commerce, the main tools for attracting and retaining target customers, taking into account their characteristics and features.

Ключевые слова: социальные сети, «Инстаграм», «ВКонтакте», «Телеграм», «Яндекс Директ», «Гугл Директ», форумы, интернет-торговля, продвижение товаров в социальных сетях и сфере «Интернет».

Key words: social networks, «Instagram», «Vkontakte», «Telegram», «Yandex Direkt», «Google Direct», forums, internet-trade, promotion of goods in social networks and the Internet.

УДК 339.13

В современных условиях развитие и продвижение информационных и интернет-технологий во всех отраслях экономики способствовало трансформации отношений между всеми участниками цепочки создания потребительской ценности: производителями и посредниками с одной стороны, с продавцами и конечными потребителями с другой стороны. Главной движущей силой преобразования взаимодействия участников цепи является электронная коммерция.

Обобщённо электронная коммерция - это деятельность по осуществлению коммерческих операций (покупка, продажа, сервисное обслуживание) с помощью электронных средств обмена данными.

Рассмотрим подходы некоторых авторов к раскрытию сущности данного понятия [2].

Таблица 1

Определение электронной коммерции

\begin{tabular}{|l|l|}
\hline \multicolumn{1}{|c|}{ Автор } & \multicolumn{1}{|c|}{ Определение } \\
\hline Л. С. Климченя & $\begin{array}{l}\text { Электронная коммерция - составная часть электронного бизнеса, а электрон- } \\
\text { ная торговля - это частный случай электронной коммерции }\end{array}$ \\
\hline О. А Кобелев & $\begin{array}{l}\text { Электронная коммерция - предпринимательская деятельность по осуществ- } \\
\text { лению коммерческих операций с использованием интернет-ресурсов }\end{array}$ \\
\hline И. Голдовский & $\begin{array}{l}\text { Электронная коммерция - это продажа товаров, при которой организация } \\
\text { спроса на товары осуществляется через Интернет }\end{array}$ \\
\hline
\end{tabular}




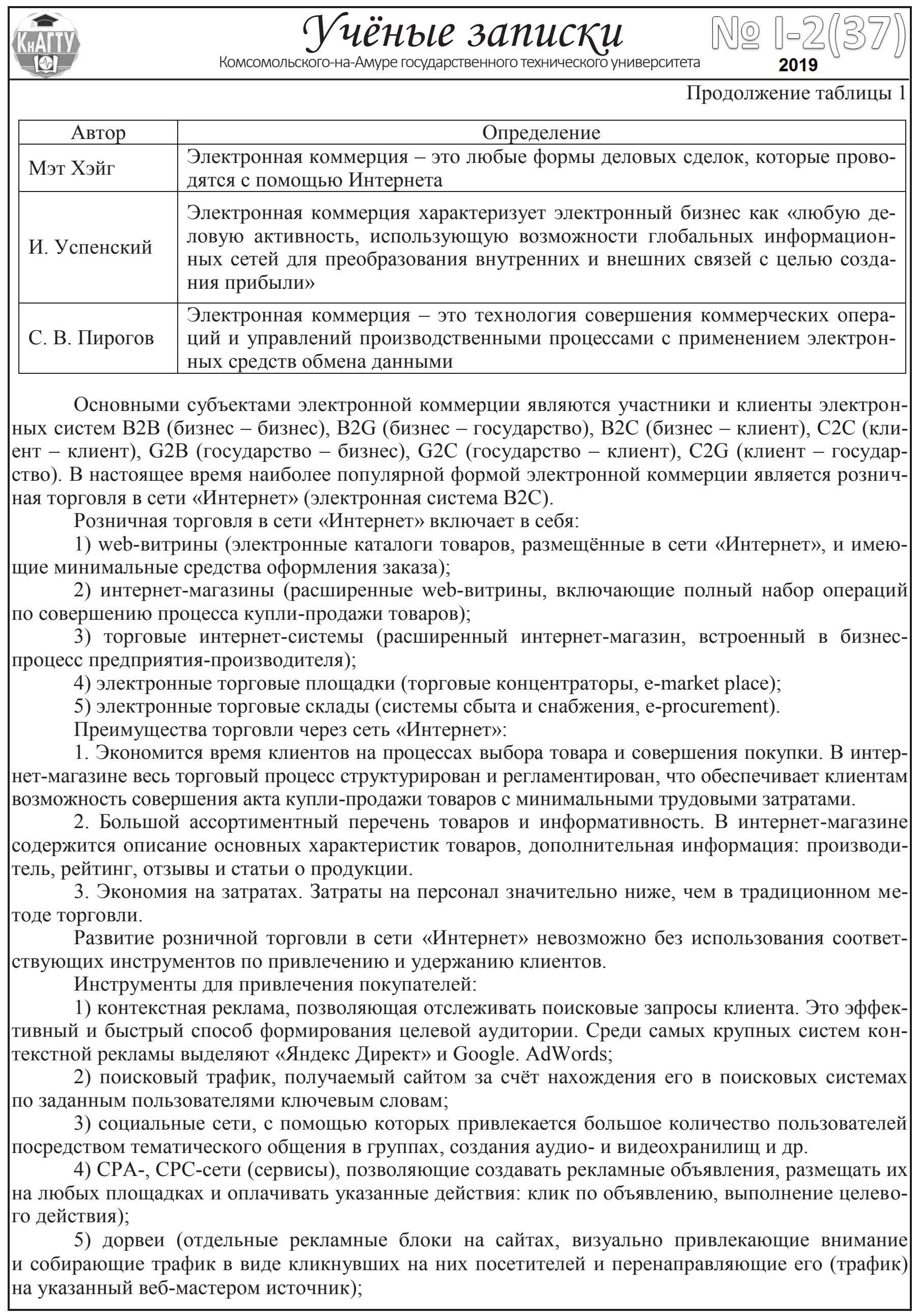


Ларченко Ю. Г., Бирюков Е. С.

ИНСТРУМЕНТЫ ПРИВЛЕЧЕНИЯ И УДЕРЖАНИЯ КЛИЕНТОВ В СЕТИ ИНТЕРНЕТ

6) реклама на целевых и тематических форумах.

Реклама на форумах делится на три вида:

a) баннерная (владелец интернет-магазина может разместить баннер на главной странице форума или в разделах тем);

б) аренда тематической темы (арендуется коммерческая ветка, в которой продавец может выкладывать товар для дальнейшей продажи, а клиенты могут оставлять свои отзывы);

в) рассылка сообщений пользователям (администрация форума может предложить владельцам интернет-магазинов рассылку по личным сообщениям).

7) вирусная реклама. Главным распространителем рекламной информации оказываются сами «получатели информации». За счёт необычной идеи, содержания, формы рекламы клиенты распространяют понравившуюся рекламу посредством Интернета, СМИ и т. д.

Выделяют 4 инструмента удержания покупателей интернет-магазинов:

1) контент: ежедневная рассылка полезных советов, ответы на вопросы, обзор новинок и форумы.

2) выстраивание отношений: сбор максимально полной информации о клиенте, индивидуализация клиентских запросов, организация обратной связи с клиентом, поздравления и подарки, бонусы и скидки за лояльность.

3) регулярность в коммуникациях: систематическая электронная интернет-переписка с клиентом.

4) сервис: простота оформления и отслеживания периода выполнения заказа, скорость обслуживания и реагирования на жалобы и предложения, возможность быстрого и бесплатного возврата товаров [1].

Сравнительная характеристика интернет-рекламы по охвату целевой аудитории и стоимости перехода показана в табл. 2.

Таблица 2

Виды интернет-рекламы

\begin{tabular}{|l|l|}
\hline \multicolumn{1}{|c|}{ Критерий } & \multicolumn{1}{|c|}{ Реклама } \\
\hline Стоимость + охват & $\begin{array}{l}\text { Контекстная реклама и поисковый трафик позволяют форми- } \\
\text { ровать поисковые запросы клиента, что обеспечивает ориен- } \\
\text { тацию на целевую аудиторию } \\
\text { Контекстная реклама платная, а поисковый трафик бесплат- } \\
\text { ный }\end{array}$ \\
\hline $\begin{array}{l}\text { Низкая и фиксированная } \\
\text { стоимость + высокий охват }\end{array}$ & $\begin{array}{l}\text { В социальных сетях есть два метода рекламы: } \\
\text { а) тематические площадки: рекламодатель приобретает ре- } \\
\text { бламу напрямую у владельца площадки } \\
\text { б) таргетированная реклама: позволяет произвести сбор целе- } \\
\text { вой аудитории, что обеспечивает ориентацию на целевую } \\
\text { аудиторию }\end{array}$ \\
\hline $\begin{array}{l}\text { Средняя стоимость }+ \text { средний } \\
\text { охват }\end{array}$ & $\begin{array}{l}\text { СРА-, СРС-сети: площадки, где рекламодатель размещает ра- } \\
\text { боту для веб-мастеров; оплата осуществляется за действия } \\
\text { (оформление заказа или регистрацию) }\end{array}$ \\
\hline $\begin{array}{l}\text { Средняя стоимость }+ \text { средний } \\
\text { охват }\end{array}$ & $\begin{array}{l}\text { Реклама на целевых и тематических форумах } \\
\text { Рекламодатель может приобрести баннер и создать тематиче- } \\
\text { скую ветку, где посетители смогут оставлять комментарии, } \\
\text { что положительно скажется на развитии магазина }\end{array}$ \\
\hline $\begin{array}{l}\text { Высокая стоимость }+ \text { высокий } \\
\text { охват }\end{array}$ & $\begin{array}{l}\text { Вирусная реклама: главным распространителем рекламной } \\
\text { информации являются сами «получатели информации» }\end{array}$ \\
\hline
\end{tabular}




\section{Учёные записки}

Комсомольского-на-Амуре государственного технического университета

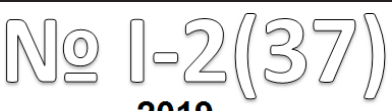

2019

В заключение отметим, что по объектам рынка основными видами интернет-рекламы являются: реклама в социальных сетях, поисковый трафик, реклама на форумах. Следовательно, продавцы продукции разных отраслей экономики в электронной коммерции ориентируются на интернет-рекламу, нацеленную на низкую - среднюю стоимость, средний - высокий охват целевой аудитории.

В качестве примера и подтверждения данного тезиса рассмотрим виды интернет-рекламы, используемой при продвижении продукции разных отраслей экономики (см. табл. 3).

Интернет-реклама по объектам рынка

Таблица 3

\begin{tabular}{|l|l|l|}
\hline \multicolumn{1}{|c|}{ Отрасль } & \multicolumn{1}{|c|}{ Интернет-магазин } & \multicolumn{1}{c|}{ Интернет-реклама } \\
\hline Автомобильная & http://www.ford.ru & $\begin{array}{l}\text { Реклама в социальных сетях } \\
\text { Реклама в видеоблогах } \\
\text { Контекстная реклама }\end{array}$ \\
\hline Текстильная & http://bfide.ru & $\begin{array}{l}\text { Поисковый трафик } \\
\text { Реклама в социальных сетях } \\
\text { Реклама на форуме }\end{array}$ \\
\hline Спортивное питание & http://Freakmass.ru & $\begin{array}{l}\text { Реклама в социальных сетях } \\
\text { Поисковый трафик } \\
\text { Реклама на форуме }\end{array}$ \\
\hline
\end{tabular}

В последующих исследованиях в продолжение раскрытия актуальности поставленной задачи планируется изучение влияния отдельных инструментов удержания целевых клиентов конкретного объекта рынка, а именно спортивного питания. В качестве основных инструментов удержания будут рассмотрены акции, скидки, конкурсы и консультации.

\section{ЛИТЕРАТУРА}

1. Борис, У. Основные виды интернет-рекламы. SeoPult: Автоматизированная рекламная сеть [Электронный ресурс] / Борис У. - Режим доступа: https://seopult.ru, свободный. - Загл. с экрана.

2. Кубкина, Ю. С. Электронная коммерция: роль, понятие, направление развития [Электронный ресурс] Ю. С. Кубкина // TERRA ECONOMICUS. - 2012. - Вып. 10, 2-2. - С. 53-55. - Режим доступа: https://cyberleninka.ru, свободный. - Загл. с экрана. 